\title{
3. The making of RECs as health research regulators
}

\section{INTRODUCTION}

The previous chapter provided a conceptual framework of RECs and their roles in regulating health research. I claimed that while research promotion-acting to advance knowledge and discovery in the interests of science and society-has been a long-standing role of RECs in the UK, that role traditionally has been situated as secondary in many (but not all) regulatory instruments and, somewhat less clearly, in practice. I claimed further that research promotion is now embedded as a twinned objective of health research regulators in law, which signals a 'flattening' of the role hierarchy of participant protection and research promotion in RECs. I use the term 'signals' because ultimately this is a claim that warrants empirical investigation. Chapters 2 and 3 provide a space to query, based on regulatory and historical analysis rather than empirical investigation, the 'trickle-down' effect this next-generation, streamlineemphasizing regulatory environment has on RECs - that is, whether RECs can be expected to encounter this twin role of protection and promotion in their work today (or before), and if so, how it is felt and operationalized in their practices. Through conceptual overview and deep historical tracing, I highlight the uneasy tension between protection and promotion, which consequently demands certain further, empirically based research that reciprocally, also helps make better sense of the historical context provided here.

This chapter steps back in time to better understand the present context, and to further set the stage for the empirical investigation and analysis presented in later chapters. I present a historical tracing of the development of RECs as health research regulators within the UK. The aim in this chapter is not to provide simply more background to the current environment, but rather to argue that there has been growth in the volume and complexity of health research regulation since the mid-20th century, with a consequent backlash against the perceived negative repercussions for research, health, and the economy. I further argue that 
RECs are a critical node in health research regulation, which is comprised of a variety of actors who may at times hold cross-cutting resources and motives. To properly examine the development of RECs and the responses by various actors to mitigate their many perceived problems (most significantly, as a bureaucratic bulwark against otherwise ethical research), we would be better served to examine the health research regulatory environment itself. This chapter claims that through significant reforms, RECs and their managing regulators have come to serve as a focal point for not only the protection of research participants, but also the sustainability and promotion of health research.

Tracing history over the past half-century, we will see that as health research gained prominence in the UK as both a driver of scientific knowledge and economic development, self-regulation of health research-ad hoc peer review by fellow scientists based on professional norms and local customs - gradually gave way to stricter, stronger, more centralized forms of regulation, particularly through policies and guidelines set by the UK's constituent governments. This was done in an effort to steer health research in an ethical manner and provide coordination and coherence for researchers, research sponsors, and the general public. In the course of this regulatory evolution, RECs became institutionalized within the NHS system (albeit haphazardly) and proliferated in number. Pressure was placed on RECs by different stakeholders to review research applications for 'consideration, comment, guidance and approval' 1 as this was seen as conforming to emerging good international practice. But this pressure led to RECs facing increased scrutiny and opprobrium from members of the research community, many of whom argued that RECs were performing the reviews poorly. The accusation was that RECs were too numerous in number, duplicative in their reviews of the same application for a multi-site project, and overly complex, opaque, and inconsistent in their functions. By the late 1990s, the picture painted by some was one of regulatory chaos rather than order. Despite a degree of reforms in the early 2000s, there remained concern about the future of health research in the UK due to ostensibly obstructive and economically destructive regulation.

Largely, these calls appear to have been answered. RECs and other parts of the research ethics oversight system have undergone substantial reform in the past decade. Partly this is due to ongoing macro-regulatory and macro-political changes occurring at the EU level that impact

1 World Medical Association, Declaration of Helsinki (World Medical Association 2013) para 23. 
Member States' national regulations. This next-generation health research regulatory reform is designed to be 'streamlined' - attuned and proportionate, calibrated to the 'scale and complexity of the research proposed'. ${ }^{2}$

The tone of the current regulatory era is reflected in the HRA's RES, which, as noted in the previous chapter, states on its website: 'We have a duty to provide an efficient and robust ethics review service that maximises UK competitiveness for health research and maximises the return from investment in the UK, while protecting participants and researchers.' ${ }^{3}$ This appeal to efficiency and a 'duty' to maximize UK competitiveness for health research and maximize the return from investment in the UK reflects an increasingly neoliberal discourse in government policy grounded in regulatory speed and considers economic optimization the central aim of governance.

The research community largely seems satisfied with the most recent reforms. The number of academic articles lamenting the state of ethics review in the UK has dwindled and transformed into praise; many look at the UK's ethics review system today with envy, viewing it as comparatively highly coordinated, efficient, and robust. ${ }^{4}$ But what do these regulatory reforms tell us about the nature of next-generation health research regulation and what its impact might be on RECs, to say nothing of its impact on research participants and publics? With the creation of the HRA in late 2011, the statutory rules promulgated under the Care Act 2014, and ensuing changes in regulatory instruments governing RECs, a key question arises: does instantiation of research promotion in law and at the governmental level of health research regulatory bodies have a trickle-down effect that impacts the day-to-day practices of individual, 'independent' RECs? Or, is law now merely reflecting a long-standing everyday practice of RECs? More broadly, has anything really changed in how ethics 'is done' by RECs, or have the changes only been at a higher, more overtly political level of legal and regulatory architecture?

2 GAfREC para 3.2.4.

3 Health Research Authority, 'Research Ethics Service and Research Ethics Committees' <www.hra.nhs.uk/about-us/committees-and-services/res-and-recs/> accessed 16 October 2019.

4 Elina Hemminki, 'Research Ethics Committees in the Regulation of Clinical Research: Comparison of Finland to England, Canada, and the United States' (2016) 14 Health Research Policy and Systems 5, 11 ('Certain features of REC work in individual countries could serve as a model for others. Streamlining of the ethics committee system in England [...] [is an example]'). 
I begin to answer these questions through a historical tracing, with the development of RECs in the UK in the late 1960s and their scattered, at times haphazard entrenchment as health research regulators in the 1970s and 1980s. Following this, I explore the formal establishment of local research ethics committees (so-called LRECs) in 1991, multi-site research ethics committees (so-called MRECs) in 1997, and the earlier incarnation of the central regulatory bodies (Central Office for Research Ethics Committees (COREC) and National Research Ethics Service (NRES)) that sought to manage them, particularly in England. I then discuss the creation of three important regulatory instruments in the early 2000s-the Research Governance Frameworks from each of the four nations, the GAfREC originally issued separately in England and Scotland, and the UK-wide Standard Operating Procedures for Research Ethics Committees (REC SOPs) - all set within the backdrop of the controversial 2001 EU Clinical Trials Directive ${ }^{5}$ and the UK's national transposition of the Directive as the Medicines for Human Use (Clinical Trials) Regulations 2004, ${ }^{6}$ which ended the bifurcated and muchmaligned LREC/MREC system and brought RECs, for the first time, within a legislative framework with imposed statutory duties.

Throughout this deep historical tracing of regulatory reform in the UK across the decades, I weave in critical commentary proffered by the research community that lobbied repeatedly for regulatory reform, particularly in the 1990s and through the first decade of the 2000s. I then discuss more recent regulatory reforms such as the introduction of the online, centralized Integrated Research Application System (IRAS) in 2004; the regulatory streamlining-oriented HRA in 2011; the Health and Social Care Act 2012; the Care Act 2014; the Central Booking Service and the online HRA Assessment Review Portal (HARP) in May 2014; the harmonized UK Policy Framework for Health and Social Care Research released in 2017 that replaces the four nations' Research Governance Frameworks; and recent government white papers and policy papers encouraging further streamlined health research regulation. I

5 European Parliament and Council Directive 2001/20/EC of 4 April 2001 on the approximation of the laws, regulations and administrative provisions of the Member States relating to implementation of good clinical practice in the conduct of clinical trials on medicinal products for human use [2001] OJ L121/34 (EU Clinical Trials Directive).

6 The Medicines for Human Use (Clinical Trials) Regulations 2004, as amended by the Medicines for Human Use (Clinical Trials) Amendment Regulations 2006, SI 2006/1928. 
reflect on the sometimes-troubled interaction between different stakeholders and RECs, which in turn, enables me to conclude with a reflection on the potential changing regulatory nature of RECs.

What I aim to show in this chapter is that while research promotion has emerged as a recent statutory phenomenon in health research regulation, it has existed, somewhat ambiguously, as a critical value throughout the history of RECs, appearing in various disguises. Similarly, participant protection has always been a driving value of, and role for, RECs; however, this has never been the sole, as opposed to primary, concern of RECs. Indeed, RECs were created as much out of pragmatic response and political necessity, driven by concerns of organizational liability and financial harm, as they were out of concern for participant protection. Participant protection and research promotion have had an uneasy, unequal, but sustained marriage across the RECs' lifespan. And along the way, REC members have faced the challenging task of working in a space that demands that they liaise with various regulatory actors and that they not only operate within the (shifting) space's confines, but also help shape its contours.

\section{REC DEVELOPMENT IN THE UK}

The notion of ethical evaluation of a proposed research project by a committee of qualified people has long been viewed by many scholars as necessary, but not necessarily sufficient, for the successful functioning of, and public trust in, health research. RECs, it is said, reflect a welldesigned and pragmatic system of 'social control' by researchers' peers and the lay public. As bioethicist William May opined in 1975: 'The primary guarantee of protection of subjects against needless risk and abuse is in the review before the work is undertaken. [...] [I]t is the only stage at which the subject can be protected against needless risk of injury, discomfort, or inconvenience.'7 Legal scholar and bioethicist John Robertson similarly concluded in 1979: 'The [REC] is an important structural innovation in the social control of science, and similar forms are likely to be developed for other such controversial areas.' ${ }^{8}$ By regulating research in an event licensing capacity - that is, by offering opinion on and ethics

7 William May, 'The Composition and Function of Ethical Committees' (1975) 1 Journal of Medical Ethics 23, 24.

8 John Robertson, 'Ten Ways to Improve IRBs' (1979) 9 Hastings Center Report 29. 
approval of a research project before it commences-RECs are seen to mitigate risks to researchers, participants, and society.

At the same time, with sustained stakeholder support and growing institutionalization through stronger forms of regulation, RECs have come to hold tremendous power over how research is shaped-and thus, what knowledge is produced-and how the relationship between a researcher and a research participant is circumscribed. As historian Laura Stark observes, ethics committees 'are empowered to turn a hypothetical situation (this study may be acceptable) into shared reality (this study is acceptable). [...] [T] hey change what is knowable.' ${ }^{9}$

How did RECs come to hold such power? As we will see, the institutionalization of RECs was a gradual, deliberate endeavour by the government to hold researchers to account, but it was devised in a way that attempted to balance government oversight with research community self-regulation. Achieving this balance was not always successful.

\subsection{Pragmatic Creation in the 1960s}

Some of the first RECs in the UK were constituted following recommendations in the 'Responsibility in Investigations on Human Subjects' policy statement, published in the Report of the Medical Research Council (MRC) for 1962-63, ${ }^{10}$ which was presented to Parliament in July 1964. However, in his ground-breaking historical study of RECs, sociologist Adam Hedgecoe carefully details how, as a whole, RECs were born not out of any particular research scandal, but rather out of the practical and economically driven necessity of British researchers to maintain funding from the well-endowed US Public Health Service. Hence, many RECs arose only after the US Surgeon General's policy from 8 February 1966, announcing that all research institutions in the US and overseas receiving Public Health Service funds for health research would have to receive prior approval from an ethics committee-a committee of the principal investigator's 'institutional associates'-based at each institution, and with each committee determining what would constitute ethical research. ${ }^{11}$ RECs were thus created as a pragmatic

9 Laura Stark, Behind Closed Doors: IRBs and the Making of Ethical Research (University of Chicago Press 2012) 5.

10 Medical Research Council, 'Responsibility in Investigations on Human Subjects' in Medical Research Council, MRC Annual Report, 1962-63 (Cmnd 2382 1963).

11 US Public Health Service, 'Memo to the Heads of Institutions Conducting Research with Public Health Service Grants from the Surgeon General', 
compromise to events unfolding in different locales and to concerns by different actors about the smooth operation of medical research and maintaining (or increasing) funding for it. Interestingly, the Thalidomide scandal of 1962 and the pioneering English whistle-blower doctor Maurice Pappworth's exposés (discussed below) had little impact on regulatory development. ${ }^{12}$ Instead, as will be seen, the defining feature of REC creation in the UK was the maintenance of the medical profession's self-regulation.

Many more RECs were created after a July 1967 report from a committee of the Royal College of Physicians of London (RCP), which recommended that each competent authority (e.g. Board of Governors, Medical School Council, Hospital Management Authority) in medical institutions across the country should ensure 'that all projects involving experimentation on humans' be approved by 'a group of doctors including those experienced in clinical investigation'.13 The RCP report was careful to warn that:

[I]t is of great importance that clinical investigation should be free to proceed without unnecessary interference and delay. Imposition of rigid or central bureaucratic controls would be likely to deter doctors from undertaking investigations, and if this were to happen, the rate of growth of medical knowledge would inevitably diminish with resultant delay in advances in medical care. ${ }^{14}$

At the same time, the RCP recognized that 'it has now become necessary for a procedure to be available for the ethical guidance of clinical investigators. The provision of such guidance would not only serve to allay understandable anxiety in the public, but would be appreciated by clinical investigators, themselves, when faced with ethical problems.' 15 The then Ministry of Health widely circulated the RCP report, providing it a form of regulatory approbation, albeit indirect. These early RECs

8 February 1966 (Department of Health, Education and Welfare 1966); Adam Hedgecoe, "A Form of Practical Machinery": The Origins of Research Ethics Committees in the UK, 1967-1972' (2009) 53 Medical History 331.

12 Duncan Wilson, The Making of British Bioethics (University of Manchester Press 2014) 44-51.

13 Max Rosenheim, 'Supervision of the Ethics of Clinical Investigations in Institutions: Report of the Committee Appointed by the Royal College of Physicians of London' (1967) 3 BMJ 429, 430.

14 Royal College of Physicians of London, Committee on the Supervision of the Ethics of Clinical Investigation in Institutions (Royal College of Physicians of London 1967) [hereinafter 1967 RCP Report] 3 (emphasis added).

15 ibid 3-4. 
were constituted only to give guidance to staff in hospitals or similar institutions. The RCP report 'deliberately' did not give specific guidance on the structure or functioning of such committees since it considered that what might be appropriate in one institution might be inappropriate elsewhere: ${ }^{16}$ according to the RCP committee, "the way in which this could best be organised must vary with different institutions'. ${ }^{17}$ A green light was given in regulatory instruments for local ways of operating RECs - as determined by the medical profession.

Pappworth's book, Human Guinea Pigs, was published in 1967, which, similar to the US whistle-blower doctor Henry Beecher's groundbreaking article a year prior, ${ }^{18}$ laid out damning evidence of unethical research carried out in the UK and other jurisdictions. ${ }^{19}$ Pappworth advocated that clinical research studies undergo prospective ethics committee review by physician-researchers' peers, with committees at each hospital board being responsible to the General Medical Council (GMC), which in turn would be answerable to Parliament. His book meant to ensure those policy recommendations were robust and implemented, but few in government read his book or bothered to take notice. As the bioethics historian Duncan Wilson notes, while Pappworth's work 'alerted the public to the ethical issues associated with clinical experiments, and contributed to a broader critique of professional expertise, it had little impact on the governance of medical research or treatment', ${ }^{20}$ Change would eventually come, but only when the self-regulating medical profession deemed it necessary in light of political and economic interest.

Still, these exposés have some importance. The value of Pappworth's and Beecher's exposés is that they augmented public dissatisfaction with research oversight on both sides of the Atlantic. As the US and UK were both undergoing rapid economic expansion in the post-war era, health research and science were seen as key drivers of progress and prosperity. But progress and prosperity could only be sustained by a robust

16 Michael Denham and others, 'Work of a District Ethical Committee' (1979) 2 BMJ 1042.

171967 RCP Report (n 14) 4.

18 Henry Beecher, 'Ethics and Clinical Research' (1966) 274 New England Journal of Medicine 1354.

19 Maurice Pappworth, Human Guinea Pigs: Experimentation on Man (Routledge \& Kegan Paul 1967). Pappworth had earlier published a damning article on the same subject. See Maurice Pappworth, 'Human Guinea Pigs: A Warning' (1962) 171 Twentieth Century 66.

20 Wilson (n 12) 50. 
regulatory system that garnered public trust and avoided scandal. In response-and when the profession felt it had to act to retain its power-the era between the late 1960s and early 1970s was marked by revolutionary regulatory enactments.

The Ministry of Health issued its first circular on RECs-HM(68)33: 'Supervision of the Ethics of Clinical Investigations'-in May 1968 to Regional Hospital Boards, Hospital Management Committees, and Boards of Governors, referring to the earlier reports of the MRC and RCP. HM(68)33 recommended that hospitals should establish ethics committees, tellingly termed 'informal advisory bodies'. As Claire Gilbert and colleagues observe of this development, hospital 'authorities were not legally required to establish ethics committees, and the committees were offered no formal legal status. No specific guidelines on practices and methods were given because it was thought that strict rules of conduct would not be adaptable to local needs.' ${ }^{21}$ And as Hedgecoe observes, the Ministry of Health seemed content to rely on the RCP as a form of regulatory 'proxy' to ensure the spread of RECs. But, the RCP's powers were limited, not least in compelling REC creation at each hospital and ensuring that hospitals (and hence the NHS and its Ministers) took legal responsibility for RECs' decisions:

It is not that RECs were not a form of self-regulation, but rather that this informal status was less the result of laissez-faire 'drift' on the part of the policy makers than a deliberate, active decision to dissociate these committees from NHS bodies and thus help preserve the idea of clinical autonomy. ${ }^{22}$

Following the request of the Chief Medical Officer in 1971 for analysis of the supervision of the ethics of clinical research in hospitals and other institutions, ${ }^{23}$ in July 1973, a further report was published by the RCP that provided details of the recommended composition and scope

21 Claire Gilbert and others, 'Diversity in the Practice of District Ethics Committees' (1989) 299 BMJ 1437.

22 Hedgecoe, “"A Form of Practical Machinery”" (n 11) 350.

23 Apparently, the Chief Medical Officer, Sir George Godber, was responding to external pressure, foremost from the Patients Association, to inquire into allegations of unethical research practices in teaching hospitals. See Jenny Hazelgrove, 'British Research Ethics after the Second World War: The Controversy at the British Postgraduate Medical School, Hammersmith Hospital' in Volker Roelcke and Giovanni Maio (eds), Twentieth Century Ethics of Human Subjects Research: Historical Perspectives on Values, Practices, and Regulations (Franz Steiner Verlag 2004) 193. 
of ethics committees, ${ }^{24}$ including a call for 'experienced clinicians with a knowledge of clinical research investigation' and a recommendation that 'there should be a lay member'. ${ }^{25}$ The report stated that 'supervision' of research ethics in an advisory role should normally be the sole function of the committee rather than as a police watchdog, and that applications should be made to an ethics committee for all proposed clinical research investigations, including trials of drugs approved under the Medicines Act 1968 and teaching demonstrations on students. ${ }^{26}$ The report stated that the object of ethics committees was 'to safeguard patients, healthy volunteers and the reputation of the profession and its institutions in matters of clinical research investigation'. ${ }^{27}$ Further, it recommended that ethics committees 'be small and they must not be so constituted as to cause an unreasonable hindrance to the advancement of medical knowledge'. ${ }^{28}$

This was the first clear regulatory statement in the UK of the role of RECs in protecting participants, but one notices that the aim of protecting participants and 'public safety' is considered as important as that of protecting researchers and institutions and 'improving rather than blocking' research. What is unclear is how exactly these two concerns of protecting participants and not unduly hindering the advancement of medical knowledge were to be reconciled by committee members. Regardless, this view towards safeguarding the medical profession's reputation and improving research while protecting participants seems to have aligned well with what REC members considered their aims to be: protecting participants but also not stifling research. In a 1979 article, members of one REC stated:

The ethical committee decided it had three main aims: firstly, to ensure that the highest ethical standards are maintained during research investigation on man while ensuring that, at the same time, research is not stifled; secondly, to ensure the protection, safety, and well being of the patient or volunteer, whether or not the procedure is to be of benefit to him; and, thirdly, to ensure

24 Royal College of Physicians of London, Committee on the Supervision of the Ethics of Clinical Research Investigations in Institutions (Royal College of Physicians of London 1973) [hereinafter 1973 RCP Report]. See also Editorial, 'Guardians of Ethics' (1973) 4 BMJ 502.

25 Editorial, 'Guardians of Ethics' (n 24).

26 Editorial, 'Local Ethical Committees: Council Approves Revised Report'

(1981) 282 BMJ 1010.

271973 RCP Report (n 24) 3.

28 ibid. 
that subjects are fully informed about any research that affects them and also that consent is properly obtained. ${ }^{29}$

The RCP's 1973 report was evidently endorsed and promoted by the government. In June 1975, HM(68)33 was replaced by HSC(IS)153: 'Supervision of the Ethics of Clinical Research Investigations and Fetal Research', which emphasized that 'all proposed clinical investigations should be referred to an ethical committee'. ${ }^{30}$ That same year, a new version of the Declaration of Helsinki was released and for the first time mentioned RECs in its guidance for ethical biomedical research: 'The design and performance of each experimental procedure involving human subjects should be clearly formulated in an experimental protocol which should be transmitted to a specially appointed independent committee for consideration, comment and guidance.' 31

By the late 1970s, RECs were a well-established feature at hospitals, but it became apparent that their remit should expand to cover much of the health research occurring outside of hospitals as well, given the growth of research in universities and stand-alone research sites. In 1974, the NHS was reorganized such that local area health authorities became responsible for clinical research conducted in all premises under their control, so many RECs began to consider research projects in the wider community and not just in a hospital. Some changed their name to reflect the larger district area and independence from any specific hospital. ${ }^{32}$ As a 1981 editorial in the BMJ reported: 'It is now apparent that the ethical committees, which were set up to review hospital-based research, should have a wider composition and cover research in all fields of medical practice.' ${ }^{33}$ Taking a cue from these regulatory developments, research funders such as the MRC began to make it a condition of funding that researchers have local ethics committee approval for research involving clinical trials and for investigations involving human subjects, whether conducted within or outwith a hospital. ${ }^{34}$ These local RECs that sprang

29 MJ Denham and others, 'Work of a District Ethical Committee' (1979) 2 BMJ 1043 (emphasis added).

30 Department of Health and Social Security, 'Supervision of the Ethics of Clinical Research Investigations and Fetal Research', HSC(IS)153 (Department of Health and Social Security 1975).

31 World Medical Association, Declaration of Helsinki (World Medical Association 1975) Principle I.2.

32 Denham and others (n 29) 1043.

33 Editorial, 'Local Ethical Committees' (n 26) 1010.

34 Ian Thompson and others, 'Research Ethical Committees in Scotland' (1981) 282 BMJ 718. 
up across the country continued to have wide latitude to interpret whether a research project was ethically acceptable.

The meta-regulatory question that would soon arise was whether the institutionalization of RECs should be spearheaded by the government or by the medical profession. As we will see, the response in the 1980s reflected the same tone as the previous decades, if not more so: strong self-regulation by the medical profession and the absence of centralizing, state-led regulatory control.

\subsection{Limited Regulation of RECs through the 1980s}

By the early 1980s, RECs were established as 'satellite regulators' of health research in multiple countries, as recommended by international guidance such as the Declaration of Helsinki and the 1982 International Ethical Guidelines for Biomedical Research Involving Human Subjects, published by the Council for International Organizations of Medical Sciences (CIOMS) in collaboration with the World Health Organization (WHO). The RCP's report from 1973 was superseded in 1984 with its now well-known Guidelines on the Practice of Ethics Committees in Medical Research (RCP Guidelines). ${ }^{35}$ As already noted in Chapter 2, the RCP Guidelines stated that RECs were 'to facilitate medical research in the interest of society' and (equally) 'to protect subjects of research from possible harm'. ${ }^{36}$ The RCP Guidelines were seen as the best 'effective standard for RECs in the UK, ${ }^{37}$ and, apparently, they were needed. As early as the late 1970 s-little more than ten years after many RECs were created-the research community maligned both the rapid growth and complexity of RECs, as well as the inconsistency in their operations in part due to reorganizations of the NHS. ${ }^{38}$ One commentator lamented:

35 Royal College of Physicians, Guidelines on the Practice of Ethics Committees in Medical Research (1st edn, Royal College of Physicians 1984).

36 ibid 1.

37 Paul McNeill, The Ethics and Politics of Human Experimentation (CUP 1993) 67.

38 Denham and others (n 29); Thompson and others (n 34). See also BT Williams, 'NHS Locally Organised Research Scheme: Regional Research Committees and the Way They Work' (1978) 1 BMJ 85; Ethical Committee, University College Hospital, 'Experience at a Clinical Research Ethical Review Committee' (1981) 283 BMJ 1312; Pauline Allen and others, 'Research Ethical Committees in 1981' (1982) 17 Journal of the Royal College of Physicians 96. 
Decentralisation of the management of the NHS locally organised research scheme was intended to enable regional health authorities to develop arrangements best suited to their local circumstances [but] [t]he variations in the structure and practice of regional research committees suggest [...] that differing standards of adjudication and review may also have resulted. ${ }^{39}$

Similarly, Ian Thompson and colleagues' survey of 34 RECs in Scotland in 1980 found that:

In their present form research ethical committees do not satisfy fully the interests of the public or the research worker. There is inadequate representation of lay interests at all levels, and with most committees maintaining strict confidentiality over their proceedings there is little other scope for public accountability. The limited use of expert assessors and capricious monitoring leave the research worker in a state of uncertainty. [...] The committees provide only limited safeguards for patients and research workers, and more effective, standardised procedures are [needed]. ${ }^{40}$

In 1982, Peter Lewis remarked that while the establishment of RECs was 'in many ways [...] an excellent thing' because it 'restrains the overenthusiastic researcher and provides protection to those who take part in research both as subjects and investigators', there were a 'number of negative aspects of the present system'. ${ }^{41}$ Among his system-level concerns was the 'institutionalization of ethics' in medical research whereby in approving a project the REC agrees 'to shoulder a portion of the investigator's responsibility', meaning the researcher 'has a measure of responsibility lifted from him and begins to act as if his actions were directed by a higher authority': 'In the state of devolved responsibility between the committee and the investigator, each can push its ethical responsibilities off onto the other.' ${ }^{2}$ Lewis also voiced concern about the procedural nature of RECs, commenting that they were 'by nature bureaucratic and process applications using guidelines which tend to become stereotyped'. ${ }^{43}$

Concerns were also raised about the inconsistency and randomness of RECs, in part a symptom of the self-regulatory, clinical autonomy paradigm supported by the government. By the late 1980s, Gilbert and colleagues noted that RECs seemed to spring up haphazardly and

\footnotetext{
39 Williams (n 38) 87.

40 Thompson and others (n 34) 718, 720.

41 Peter Lewis, 'The Drawbacks of Research Ethics Committees' (1982) 8 Journal of Medical Ethics 61.

42 ibid 61-2.

43 ibid 62.
} 
idiosyncratically across the country: some within hospitals, others independently but with responsibility to a district health authority or management team that appointed them, and others within pharmaceutical companies for Phase 1 clinical trial studies. ${ }^{44}$ RECs were, in other words, operating in a hybrid regulatory space where they were seen as underregulated regulators but themselves over-regulating health research. In part, this was due to the government's explicit position of deferring regulatory authority to the medical profession and, in line with the 1980s neoliberal ethos, even removing regulation where they could. Hedgecoe and others have noted that in the early 1980s (and until the coming into force of the Clinical Trials Regulations 2004), the government deregulated areas of biomedical research such as Phase 1 clinical trials to encourage more clinical trials (and thus investment) in the country, all but removing regulatory oversight from the Medicines Division of the Department of Health and Social Security and later the Medicines Control Agency (the predecessors of the Medicines and Healthcare products Regulatory Agency, or MHRA), and placing both ethics and scientific review within RECs alone. ${ }^{45}$ While RECs could be a thorn in the sides of researchers, RECs typically were less stringent than drug regulators, especially from a methodological and scientific standpoint, and were one less regulatory authority from which researchers and sponsors would need to secure approval.

But all the same, many commentators found the REC system Byzantine. RECs were public, private, institutional, and regional. The prevailing opinion was that the only common approach of RECs was to bewilder researchers and stifle research. Few were clear as to the remit and scope of their review, much less the standards by which they undertook evaluation of a research proposal. The RCP Guidelines were revised in 1990, but it had become apparent to many in the research community that under-regulated, inconsistent RECs were too damaging to research, despite the fact that most REC members were researchers or clinicians themselves, and guidance from the RCP encouraged them to facilitate research. Guidelines were not enough, many felt; it was time for the government to step in and attempt to achieve some marked level consistency in how these committees were structured and how they functioned. As an editorial in the BMJ in 1990 opined, citing articles recently published by researchers in its own journal and a report

44 Gilbert and others (n 21).

45 Adam Hedgecoe, 'A Deviation from Standard Design? Clinical Trials, Research Ethics Committees, and the Regulatory Co-Construction of Organizational Deviance' (2014) 44 Social Studies of Science 59, 63. 
published by the Institute of Medical Ethics in 1986:46 'evidence suggests that the ethical control of medical research remains inconsistent and ineffective', 'sensible suggestions about the structure and process of ethics committees have been widely ignored', and '[t]hirty years should have been adequate for ethics committees to get their act together, yet there are still wide discrepancies in their constitution and working' ${ }^{47}$

The problem was that no regulatory network or central health research regulatory authority existed for distributing guidelines and standards to achieve procedural and substantive consistency, ${ }^{48}$ and many RECs seemed to ignore the RCP Guidelines and operate as they pleased, revelling in what was little more than self-regulation and local control within a health district. Julia Neuberger's in-depth empirical investigation of RECs across the UK in the early 1990s found that it was lack of statutory regulation of RECs that caused the most serious problems, including researchers not taking RECs seriously. In short, Neuberger found that RECs were fundamentally disempowered regulators of research. 'RECs have not hitherto followed guidelines particularly closely', she reported; they 'lack power, being advisory to [district health authorities] and other appointing authorities, and have no policing or monitoring role' ${ }^{49}$ Her stark conclusion was that RECs were neutered regulators:

However hard they work, however thorough their examination of research protocols on a case-by-case basis, however much better constituted and trained, and however well supported they may be administratively, unless they have the power to ensure that all research is submitted to them and to stop research that they regard as unethical, they will not be taken sufficiently seriously. For these reasons and others, this report, whilst making detailed recommendations for improvements to present practice, recommends that there should be proper legislation. ${ }^{50}$

46 Institute of Medical Ethics, Research Ethics Committees in England and Wales: The Institute's Survey (Institute of Medical Ethics 1986, Supplement No 2).

47 Stephen Lock, 'Monitoring Research Ethical Committees' (1990) 300 BMJ 61.

48 Michael Gelder, 'A National Committee for the Ethics of Research' (1990) 16 Journal of Medical Ethics 146.

49 Julia Neuberger, Ethics and Health Care: The Role of Research Ethics Committees in the United Kingdom (King's Fund Institute 1992) 8.

50 ibid (emphasis added). 


\subsection{Formal LREC/MREC Establishment and Further Criticism in the $1990 \mathrm{~s}$}

On the heels of Neuberger's investigation, a degree of regulatory clarity came in August 1991 when the Department of Health issued Health Service Guideline (91)5: 'Local Research Ethics Committees', which replaced HSC(IS)153 from 1975 and formally introduced LRECs in England. (Wales and Scotland passed their own guidelines to establish LRECs in 1991 and 1992, respectively. ${ }^{51}$ ) Hedgecoe observes that this 'marked the point where power over the shape of ethics review shifted from the medical profession (in the form of the RCP) to central government. ${ }^{52}$ The Health Service Guideline, colloquially referred to as 'the Red Book', stated that 'every [NHS] health district should have a local research ethics committee to advise NHS bodies on the ethical acceptability of research proposals involving human subjects' ${ }^{53}$ LRECs would scrutinize research projects involving patients from within the specific health authority. Thus, each LREC acted on behalf of and for the local health authority in an advisory capacity, so it was ultimately the NHS body (e.g. NHS Trust, Special Health Authority) that would decide whether a project should go ahead. However, no sanctions for noncompliance were mentioned in the Red Book and thus NHS institutions were not compelled to adopt the guidelines and institute LRECs.

This regulatory guidance and the Department of Health taking responsibility for RECs failed to quell the research community's criticism of RECs. And, arguably because the guidance was not statutory regulation as advocated by commentators such as Neuberger, RECs were still not taken 'sufficiently seriously' by many researchers. ${ }^{54}$ Neuberger's report was written just after the Red Book's release; analysing the new guidance, she concluded that 'whilst their tone is tougher than that of previous versions, they lack the detailed discussion of the RCP guidelines'. ${ }^{55}$ Neuberger also observed that the Red Book differed somewhat

51 See Welsh Government, Welsh Health Circular WHC(91)75; Scottish Office, Department of Health, NHS Circular 1992(GEN)3.

52 Adam Hedgecoe, 'Scandals, Ethics, and Regulatory Change in Biomedical Research' (2017) 42 Science, Technology, \& Human Values 577, 585.

53 Department of Health, 'Local Research Ethics Committees', HSG(91)5.

54 See also Hedgecoe, 'Scandals' (n 52), who argues that the Red Book was a reflection of two strands of thinking common in the 1980s: the need to standardize RECs to protect the interests of researchers and to reduce the influence of the medical profession.

55 Neuberger (n 49) 13. 
in substance from the $1990 \mathrm{RCP}$ Guidelines (having superseded the original 1984 version). The Red Book suggested that multi-centre research could be approved by a single LREC, whose decision would then be accepted by other committees, but the details were not specified and so, unsurprisingly, this never happened. Each LREC sought to approve research conducted in its health district, regardless of the outcome of reviews conducted by LRECs elsewhere. Though some RECs voluntarily entered into local arrangements to recognize other local REC decisions, this was by no means universal and rarely extended beyond a single health authority boundary. ${ }^{56}$ The light-touch regulatory approach from the Department of Health only served to exacerbate REC differentiation across the country. By this time, there were over 200 RECs across the UK. Studies from the mid-1990s indicated that large variations in application requirements, review procedures, and opinions occurred in practice among different LRECs. ${ }^{57}$ The level of support and accountability of RECs to their appointing authorities were equally variable. ${ }^{58}$ Calls for a common, standardized research application form were widespread in medical and science journals. Despite the introduction of SOPs for LRECs in $1994,,^{59}$ members of the research community continued to express discontent with stifled health research due to RECs.

The REC structure was partially modified in 1997 when new Department of Health guidelines sought to simplify the procedure for ethics review of multi-centre studies. $\mathrm{HSG}(97) 23^{60}$ required research studies

56 Clive Collett, 'Setting the Strategic Landscape for the HRA: Ethics Governance' (2013) (unpublished internal HRA paper provided to the author).

57 George Alberti, 'Local Research Ethics Committees: Time to Grab Several Bulls by the Horns' (1995) 311 BMJ 639; Paul Garfield, 'Cross District Comparison of Applications to Research Ethics Committees' (1995) 311 BMJ 660; Claire Middle and others, 'Ethics Approval for a National Postal Survey: Recent Experience' (1995) 311 BMJ 659; Alison While, 'Ethics Committees: Impediment to Research or Guardian of Ethical Standards?' (1995) 311 BMJ 661.

58 Collett (n 56).

59 See Christine Bendall, Standard Operating Procedures for Local Research Ethics Committees: Comments and Examples (McKenna and Company 1994); Christine Bendall and J Riddell, Using Standards for Local Research Ethics Committees: A Guide to Using the Framework of Standards and the Standard Operating Procedures (NHS Training Division 1994); Leigh and Baron Consulting Limited and Christie Associates, Standards for Local Research Ethics Committees: A Framework for Ethical Review (Department of Health 1994).

60 Equivalent guidance was published in Wales and Scotland: DGM 98/25 and MEL 97/8, respectively. According to the original GAfREC, MRECs 
conducted in the UK that involved four or more LREC geographic localities (i.e. four or more health authority boundaries) to have approval from both a single 'MREC' in the country (out of 13 that eventually existed), and the LREC for each participating site. As a Department of Health document noted, the rationale for the MREC creation was to streamline research governance processes to improve the environment for clinical trials:

[the] reasons for streamlining the system for LREC review of multi centre trials $[\ldots][$ are $][\ldots]$. To contribute to improved clinical outcomes by approving potentially beneficial research more efficiently [...]. To reduce delays to good research [...] [and] [...]. To avoid a large number of LRECs all devoting time to the same aspects of identical protocols. ${ }^{61}$

The MREC system was overseen by the NHS Research and Development Directorate (and was directly accountable to the Department of Health), whereas LRECs were overseen by regional health authorities. Research could not proceed until each LREC informed the approving MREC of its lack of objection with respect to 'locality issues', which were later specified in the first edition of the GAfREC released in 2001. This meant that LRECs could provide advice about the local acceptability of a protocol and could reject the research protocol for 'locality issues', but could not amend the study protocol or the study instruments. One MREC approval would be valid throughout the UK; if the MREC declined to give a favourable opinion on the application, any existing approval by LRECs still stood, but those LRECs had to be informed of the MREC's decision.

Despite this regulatory change that was intended to smooth approvals for multi-site research, many researchers found that, in practice, MREC

'undertake the review of the ethics of the research protocol, including the content of the patient information sheet and consent form. No further ethical review of these items shall be undertaken by other RECs (except in the process of a "second review" [...]).' See Department of Health, Governance Arrangements for NHS Research Ethics Committees (Department of Health 2001) para 8.7. Locality issues undertaken by LRECs were 'limited to': 'the suitability of the local researcher; the appropriateness of the local research environment and facilities; specific issues relating to the local community, including the need for provision of information in languages other than English'. ibid para 8.8.

61 Department of Health, 'Review of Ethics of Multi-Centre Trials', February 1995, CMO's Consultative Group on Research Ethics, RE/95/1, NPA, as quoted in Hedgecoe, 'Scandals' (n 52) 586. 
approval did not necessarily lead to more efficient and cost-effective LREC approval. ${ }^{62}$ As Collett notes:

Many local RECs did not trust these newly-formed MRECs and were unhappy to relinquish their perceived responsibility for the ethical review of research projects taking place within their patch. This often resulted in lengthy delays whilst LRECs and the MREC disagreed over ethical issues occasionally resulting in the local REC refusing to approve the study for their local site. ${ }^{63}$

In summary, though RECs in the NHS system have existed sporadically and informally since the late 1960s, they had no formal standing until guidance was put forth by the Department of Health in 1991, and it must be emphasized that this was only guidance. Through the 20th century, then, RECs in the UK were simply ungoverned by statutory regulation. Until the 21st century, when statutory regulations were introduced that legally required REC review and approval for certain types of health research, there was no legal requirement for health researchers to obtain prior REC approval, and there was no statutory regulation that governed the practices of RECs. This is not to say that the impact of REC practices was unfelt by researchers. On the contrary, as we have seen, their impact on controlling research was profound. RECs' informal and extra-legal authority was acute, and for many researchers, deeply troubling. Clinical autonomy and self-regulation would have to be reined in.

\section{CENTRALIZATION AND LEGISLATION IN THE NEW MILLENNIUM}

By the late 1990s, RECs had become an established if maligned feature in health research regulation. In response to (1) criticisms that the functions and standards of RECs were imprecise and harmful to valuable research; (2) the coming into force of the EU Clinical Trials Directive; and (3) the North Staffordshire research scandal that erupted in the

62 Rustam Al-Shahi and Charles Warlow, 'Ethical Review of a Multicentre Study in Scotland: A Weighty Problem' (1999) 33 Journal of the Royal College of Physicians of London 549; Isobel Larcombe and Martin Mott, 'Multicentre Research Ethics Committees: Have They Helped?' (1999) 92 Journal of the Royal Society of Medicine 500; Nicholas Dunn and others, 'Costs of Seeking Ethics Approval Before and After the Introduction of Multicentre Research Ethics Committees' (2000) 93 Journal of the Royal Society of Medicine 511.

63 Collett (n 56) 4 (emphasis in original). 
1990s, RECs underwent significant changes in the new millennium. They became governed by a variety of governance mechanisms-including top-down, state-led commands and controls - that sought to make them work efficiently and harmoniously, and in so doing, impacted more directly how they worked. In the early 2000s, a flurry of guidance, tools, and processes from the UK's Health Departments emerged to 'update' RECs to make the process smoother for researchers and more robust for the public interest, including the establishment of the COREC in 2000; a Research Governance Framework in 2001; GAfREC in 2001; the requirement for a single UK-wide REC opinion in 2004 that replaced the LREC/MREC system; formalized UK-wide SOPs for RECs in 2004; an online Research Ethics Database (RED) to enable REC administrators to import application data and documentation and to process and control research applications through to the approvals stage and to record and track post-approval activity; and the creation of an online portal to submit research applications (today known as IRAS) in 2004.

Yet the sharp growth of health research regulation through guidelines and frameworks that sought to make RECs more efficient, consistent, and robust in their processes - coupled with the passage of three major Parliamentary statutory instruments on clinical trials, human tissue, and mental capacity-led to a perception that research was getting further buried in paperwork and bureaucratic acronyms, and that RECs were getting papered over but not fundamentally reformed. As RECs were created before there was any national legal requirement for their use or adherence to a governing framework, consistency, effectiveness, and cooperation were long-standing challenges. Regulatory add-ons did not remedy the problems identified by many, or if they managed to plug the hole on one issue, others would appear. Deeper regulatory solutions were called for to solve the problems created in part by misaligned, siloed regulation itself.

Researchers were frustrated with the growing amount of bureaucracy in the system. ${ }^{64}$ Some felt that the process of acquiring ethics approval

64 Hilary Hearnshaw, 'Comparison of Requirements of Research Ethics Committees in Eleven European Countries for a Non-Invasive, Interventional Study' (2004) 328 BMJ 140; Glyn Elwyn and others, 'Ethics and Research Governance in a Multicentre Study: Add 150 Days to Your Study Protocol' (2005) 330 BMJ 847; Nina Fudge and others, 'Streamlined Research Governance: Are We There Yet?' (2010) 341 BMJ c4625; Andrew Thompson and Emma France, 'One Stop or Full Stop? The Continuing Challenges for Researchers Despite the New Streamlined NHS Research Governance Process' (2010) 10 
was 'so onerous that it is compromising clinical research', 65 and that the system had become a 'rather prescriptive, bureaucratic and rigid process', with 'a fairly standardized review procedure and application form, leading to standardised research procedures'. ${ }^{66}$ Researchers were particularly unhappy with having to obtain both REC approval and 'R\&D permission' (i.e. research governance permission) from each of the NHS service providers (e.g. NHS Trusts) involved in their research project, as established in the second editions of the Research Governance Framework.

Over-regulation and a disproportionate approach to research presenting low risk were seen as the main problems. As one group of researchers intoned: 'In a risk-benefit arena that is now heavily stacked towards perceived risk, the instigators of over-regulation must bear responsibility for the real and emerging risks of a failure to deliver the potential lifesaving benefits of clinical research promptly.' 67

Coupled with their criticisms, clinicians and researchers invoked the rhetoric of research 'promotion'. For example, in a BMJ editorial in 2000, the then President of the RCP insisted the REC system needed to be improved as it was obstructing 'research that will in the long run improve health care and health'-which was one of the 'two major functions' of a REC, along with protecting participants and the public from possible harm. ${ }^{68}$ This positioning was strategically important, as continuing to frame RECs as carrying two equally important roles would enable the research community, including the powerful and politically connected RCP and AMS, to lobby the UK government for favourable changes to the research regulatory and governance structure.

In the following sections, I trace the steps of deep regulatory reform in the new millennium with a view to demonstrating that the reform was in direct response to criticisms made by the research community (and its

BMC Health Services Research 124; Helen Snooks and others, 'Bureaucracy Stifles Medical Research in Britain: A Tale of Three Trials' (2012) 12 BMC Medical Research Methodology 122; John Barry, 'Improvements to the Ethical Review Process are Good News for Psychologists and Health Researchers in Europe, Especially in the UK' (2012) 8 Europe's Journal of Psychology 1.

65 Louise Robinson and others, 'NHS Research Ethics Committees' (2007) 335 BMJ 6.

66 Sue Richardson and Miriam McMullan, 'Research Ethics in the UK:

What Can Sociology Learn from Health?' (2007) 41 Sociology 1115, 1119.

67 Paul Stewart and others, 'Regulation: The Real Threat to Clinical Research' (2008) 337 BMJ a1732.

68 George Alberti, 'Multicentre Research Ethics Committees: Has the Cure Been Worse Than the Disease?' (2000) 320 BMJ 1157, 1158. 
representative bodies), and that the reform was to be led by the central government, which instantiated the dual roles of participant promotion and research promotion at the level of legal architecture.

\subsection{0-10: A Series of Fundamental Reforms}

To address the continuing concerns about the processes around ethics review, and to help RECs prepare for future implementation (in May 2004) of the EU's Clinical Trials Directive 2001/20/EC, England's Department of Health established COREC in 2000. COREC's mission was to improve the system of operation of RECs and to advise the Department of Health on necessary policy requirements concerning their operation. ${ }^{69}$ COREC took on the administrative functions for MRECs and provided management support for LRECs, including through local Offices for Research Ethics Committees (ORECs) situated across ten sites in England, with each led by an OREC Manager. The local health authorities (Health Boards and Strategic Health Authorities) remained the appointing authorities for the LRECs. While COREC acted for the Department of Health in England, it 'also provided a focus for discussion and collaboration with the relevant bodies and individuals in Wales, Scotland and Northern Ireland. It undertook most of the development work to create a common UK system' for RECs. ${ }^{70}$ Among the procedural changes instituted by COREC early in the new millennium was the creation of a Central Allocation System in 2004, a common UK-wide ethics application form, and standard opinion letters issued by RECs. Even so, some researchers criticized the application form for being too long and cumbersome. ${ }^{71}$

In March 2001, the Department of Health published the first edition of the Research Governance Framework for Health and Social Care (RGF), which set forth a quality and accountability framework within which research was to be undertaken in the NHS. ${ }^{72}$ Both the RGF and GAfREC were created partly in response to a report published in May 2000 that looked into the North Staffordshire scandal, where from 1990 until 1993, it was alleged that premature infants in North Staffordshire Hospital had been put into a controlled trial of an alternative type of ventilator without

\footnotetext{
69 Collett (n 56).

70 ibid 4.

71 Konrad Jamrozik, 'Research Ethics Paperwork: What is the Plot We Seem to Have Lost?' (2004) 329 BMJ 286.

72 Scotland and Wales published a similar RGF that same year. Northern Ireland did not publish its first RGF until 2006.
} 
their parents' knowledge or consent. ${ }^{73}$ Allegations of lack of informed consent were first raised by a group of parents in the late 1990s, when apparently they first became aware that their infants had been enrolled in the controlled trial. The subsequent report, led by Professor Rod Griffiths, recommended a major overhaul of the way in which all clinical research was to be conducted in the NHS, including establishing 'formal guidance on research governance within the NHS' in the form of a national research governance framework, ${ }^{74}$ as well as clear governance arrangements for RECs. The government accepted the key recommendation and began crafting a research governance framework in $2000 .^{75}$

Notably, the RGF reinforced the language from previous guidance documents in the UK (especially the RCP Guidelines) that emphasized RECs should also facilitate research:

Their primary responsibility is to ensure that the research respects the dignity, rights, safety and well-being of individual research participants. They should also work efficiently to facilitate the good conduct of high quality research that offers benefits to participants, services and society at large. Unjustified delay to such research is itself unethical. ${ }^{76}$

Elsewhere, the RGF also identified RECs as holding two 'key responsibilities', namely: 'ensuring that the proposed research is ethical and respects the dignity, rights, safety and well-being of participants'; and 'assuring the scientific quality of proposed research'. ${ }^{77}$

Working with COREC, the Department of Health also released in July 2001 its GAfREC, which replaced the previous guidance issued under

73 The RGF also built on several documents published to support the government's modernization agenda of the NHS. See e.g. Department of Health, The New NHS: Modern, Dependable (Department of Health 1997).

74 NHS Executive West Midlands Regional Office, Report of the Review into the Research Framework in North Staffordshire Hospital NHS Trust (NHS Executive 2000) para 4.1.2.

75 Hedgecoe observes, however, that: 'The [Griffiths] panel's recommendation for the revision of research governance in the NHS was not an original consequence of the [North Staffordshire] scandal, but rather fed into changes that were already underway, and indeed were in part shaped by broader regulatory changes at a European level [...], rather than a national research scandal.' See Hedgecoe, 'Scandals' (n 52) 589. In other words, the Department of Health was already beginning to develop a research governance framework; the Griffiths report simply provided further impetus for regulatory reform.

76 Department of Health, Research Governance Framework for Health and Social Care (Department of Health 2001) para 3.12.2.

77 ibid 20. 
cover of HSG(91)5 (which established LRECs) and HSG(97)23 (which established MRECs). Scotland published an equivalent GAfREC in October that same year. ${ }^{78}$ Sensing that MRECs and LRECs were not operating efficiently, the GAfREC were drafted as guidance to provide 'a standards framework for the process of review of the ethics of all proposals for research in the NHS and Social Care which is efficient, effective and timely, and which will command public confidence.'79 Meant to be read in conjunction with the RGF, the 34-page GAfREC (and its subsequently longer versions published in 2011 and 2018) set out 'general standards and principles for an accountable system of RECs' ${ }^{80}$ In line with prevailing international ethics guidelines such as the Declaration of Helsinki and the Council of Europe's Convention for the Protection of Human Rights and Dignity of the Human Being (known as the Oviedo Convention), ${ }^{81}$ and more clearly stated than in the RGF, the GAfREC declared RECs as having 'primary' and 'secondary' responsibilities:

RECs are responsible for acting primarily in the interest of potential research participants and concerned communities, but they should also take into account the interests, needs and safety of researchers who are trying to undertake research of good quality. However, the goals of research and researchers, while important, should always be secondary to the dignity, rights, safety, and well-being of the research participants. ${ }^{82}$

Together, both the RGF and the GAfREC signalled a subtle shift in the evolutionary development that was emerging in the UK. These regulatory instruments certainly did not jettison research promotion as a responsibility of RECs; rather, they clarified that the UK's RECs would be mandated with a primary role shared with RECs in other countries, and which heeded the message of international ethics guidelines, namely that in assessing the ethical acceptability of research, participant protection must always take precedence over the interests of research and researchers.

78 Scottish Government Health and Wellbeing Directorate, Governance Arrangements for NHS Research Ethics Committees in Scotland (Scottish Government Health and Wellbeing Directorate 2001).

79 GAfREC Preface.

80 ibid.

81 Convention for the Protection of Human Rights and Dignity of the Human Being with Regard to the Application of Biology and Medicine: Convention on Human Rights and Biomedicine (1997), art 2.

82 GAfREC para 2.3. 
To comply with and give domestic effect to the EU Clinical Trials Directive (2001/20/EC), the UK passed the Medicines for Human Use (Clinical Trials) Regulations 2004, ${ }^{83}$ operative from 1 May 2004. Ushering in 'root and branch reform' and arguably marking 'the end of the self-regulation of research ethics', ${ }^{84}$ the Clinical Trials Regulations 2004 established NHS RECs on a legal basis for the first time, providing detailed provisions on their composition and what RECs must, as a statutory duty, consider in preparing their ethics opinion. ${ }^{85}$ The EU Clinical Trials Directive, under Article 6 in particular, required Member States to establish RECs and to have RECs approve clinical trial protocols. According to Article 7, for multi-centre clinical trials limited to the territory of a single Member State, Member States had to establish a procedure providing, notwithstanding the number of RECs in its territory, for the adoption of a single opinion for that Member State. In the case of multi-centre clinical trials carried out in more than one Member State simultaneously, a single opinion would be required for each Member State concerned by the clinical trial. Thus, the Clinical Trials Regulations 2004 provided for a single UK-wide opinion for multi-centre studies. They also set a defined time period (60 days) for issuing an ethics opinion. To avoid the confusion that would result from having parallel but different operating ethics review systems, the four UK Health Departments agreed to make it a policy to apply this approach of single REC review also to all health research within the NHS involving individuals, their organs, tissue, or data-not just clinical trials.

Also in 2004, version 1.0 of the UK-wide REC SOPs was produced to meet the obligations of the EU Clinical Trials Directive for the operation of ethics committees in relation to CTIMPs. As previously mentioned, the SOPs included provision for a single UK-wide ethics opinion on all types of health research, thus reducing if not eliminating the duplication

83 The Medicines for Human Use (Clinical Trials) Regulations 2004, as amended by the Medicines for Human Use (Clinical Trials) Amendment 2006, SI 2006/1928. The amended Regulations were intended to give domestic effect to the EU's Good Practice Directive (2005/28/EC).

84 Susan Kerrison and Allyson Pollock, 'The Reform of UK Research Ethics Committees: Throwing the Baby out with the Bath Water?' (2005) 31 Journal of Medical Ethics 487.

85 See e.g. the Medicines for Human Use (Clinical Trials) Regulations 2004 reg 15(5). This said, the first statutory regulation to establish a REC was the Adults with Incapacity (Ethics Committee) (Scotland) Regulations 2002 (2002 No 190), which established a REC as per section 51 of the Adults with Incapacity (Scotland) Act 2000 (AWI Act). This REC is today referred to as the Scotland A REC. 
and inconsistency in opinions rendered by RECs for multi-site studies. The SOPs obligated RECs to render a decision on any individual application within 60 days, unless the REC asked for more information (in which case the 'clock' stopped until that information was received).

New statutory and regulatory developments required RECs to consider the ethical implications of research in areas previously not considered or minimally considered. The Human Tissue Act 2004 was passed to govern the collection and use of human tissue (or 'relevant material' as the Act states), including for research purposes, in England, Wales, and Northern Ireland. ${ }^{86}$ The Mental Capacity Act 2005 followed thereafter, again imposing greater responsibilities for RECs, this time for research involving adults lacking mental capacity. Organizational changes also occurred; following the Department of Health's Arm's Length Body Review, ${ }^{87}$ the National Patient Safety Agency (NPSA) took over responsibility for COREC in April 2005.88

In April 2005, largely in response to the EU Clinical Trials Directive, the second edition of the RGF was published by the Department of Health; the three other UK nations also published their own shortly thereafter. ${ }^{89}$ As noted by the Scottish RGF (and in language used verbatim in the Welsh and Northern Irish RGFs), and in contradistinction to the first edition of the RGF and the GAfREC, the goal of the document was to set out a 'balance' between participant protection and research promotion:

The change in the law stimulated wide debate on good practice and regulatory process in collaborative trials. The lessons drawn are visible throughout this edition [of the RGF] and recognise the need to achieve a proper balance by

86 Scotland passed its own Human Tissue (Scotland) Act 2006, with different governance arrangements. The UK's Human Tissue Authority performs certain tasks on behalf of the Scottish Government, however. All NHS RECs in Scotland are recognized by the other three UK Health Departments for the purposes of the Human Tissue Act 2004, which means that a Scottish REC can give UK-wide approval for research involving human tissue.

87 Department of Health, Reconfiguring the Department of Health's Arm's Length Bodies (Department of Health 2004).

88 Existing since July 2001, the NPSA was a special health authority covering England and Wales and coordinated system-wide NHS patient safety functions. It was abolished in 2012.

89 Scotland published the second edition of its Research Governance Framework in 2006; Wales followed suit in 2009 (Northern Ireland published its first edition in 2006). 
safeguarding the rights of patients involved in clinical trials while avoiding a disproportionate impact on those who carry them out. ${ }^{90}$

The English RGF, however, phrased its preface to the second edition differently, emphasizing a risk-based regulatory approach and the need to still primarily protect participants:

Regulations on clinical trials involving medicines took effect in 2004. The change in the law stimulated wide debate on good practice and risk-based regulatory process. We have drawn lessons throughout this edition. [...] There has been new legislation on human tissue and on mental capacity, with provisions to protect those who participate in research. Whatever the context, the interests of research participants come first. Those responsible must be satisfied they have taken all reasonable steps to protect the dignity, rights, safety and wellbeing of participants. We have to be frank about risks, and businesslike about managing them. ${ }^{91}$

As clinical researchers continued to express publicly concerns that RECs were burdensome and 'impeded, delayed, and sometimes distorted research', 92 in late 2004, the UK government appointed an advisory group led by the then Minister of Health Lord (Norman) Warner to review the operation of RECs regulating research in the NHS in England. The review had explicit economic and regulation-streamlining aims. It was to consider 'regulatory blocks impeding research';93 'developments and trends affecting the remit, administration, operation and workload of NHS RECs in England';94 and 'options for investment and measures to contain recurrent costs'. ${ }^{95}$ The review was to recommend, among other things, 'how to reduce the time required of researchers starting high quality research'; 'provide for a single point of entry, consistent process,

90 Scottish Executive Health Department, Research Governance Framework for Health and Community Care (Scottish Executive Health Department 2006) Preface.

91 Department of Health, Research Governance Framework for Health and Social Care (Department of Health 2005) Foreword.

92 Susan Mayor, 'Advisory Group to Review NHS Research Ethics Committees' (2004) 329 BMJ 1258.

93 Department of Health, Report of the Ad Hoc Advisory Group on the Operation of NHS Research Ethics Committees (Department of Health 2004) [hereinafter Lord Warner Report] 17.

94 ibid. This said, observers included representatives from Scotland, Northern Ireland, and Wales in recognition of the UK Health Departments' aim to maintain a UK-wide system for ethics review.

95 ibid. 
and single decision appropriate for all the types of research requiring a NHS REC's opinion'; and 'strengthen the systems, structures and processes supporting NHS RECs to make their business process as efficient as possible and improve users' and committee members' experience of it'. The ad hoc advisory group published their report in June 2005.

Critically, this Lord Warner Report at times stressed a dual role of RECs to protect participants and promote research: "[T]he role of Research Ethics Committees is both to protect the interests of human participants in research and to promote research that is of real value. ${ }^{96}$ Yet elsewhere, the report suggested that the roles were not twinned, but rather, as stated in the GAfREC, primary and secondary:

It should remain the role of research ethical review to safeguard the rights, dignity, safety and welfare of potential human research participants by providing an independent opinion on the ethical implications of a research proposal. [...] Research of relevance and good quality is essential to underpin further developments in health and social care. This gives Research Ethics Committees a secondary role - to facilitate ethical research. ${ }^{97}$

The Lord Warner Report noted that 'many of the criticisms' they heard from researchers 'reflect pent-up frustration with the operation of the REC system over a number of years, and do not always take account of improvements that COREC has introduced more recently'. ${ }^{98}$ Thus, 'major improvement in the efficiency of the process of ethical review in the very recent past $[\ldots]$ has not yet been fully appreciated' ${ }^{99}$ Nonetheless, the report acknowledged that some criticisms were valid, including unexplainable inconsistencies among RECs and overcapacity in the number of RECs (i.e. too many RECs 'with very small workloads' ${ }^{100}$ ). Systemic reform was urged: 'The achievements of the ethical review system attained so far, whilst impressive, have been largely incremental. The time has now come for a step change in the system of RECs, to address perceived weaknesses in the system, and provide better support for Chairs, members and administrative staff.' ${ }^{101}$ Among the report's nine recommendations were further rationalizations of the number of RECs in

\footnotetext{
96 Lord Warner Report (n 93) para 2.6.

97 ibid Conclusions, paras 1-2.

98 ibid para 2.5.

99 ibid Conclusions, para 4.

100 ibid para 3.6.

101 ibid 15.
} 
England, 'with more intense operation for the smaller number resulting';102 the creation of 'Scientific Officers' in COREC to support the work of RECs; improvements to the national application form and application process; improvements to quality assurance and training; substantial improvement to local R\&D procedures and their interaction with REC review; and a more proportionate review process, that is, excluding from REC review 'surveys or other non-research activity if they present no material ethical issues for human participants' ${ }^{103}$

Following the Lord Warner Report, in August 2006 COREC released its response publication, Building on Improvement, based on consultation with stakeholders. COREC highlighted its role both to facilitate research and help RECs protect participants. ${ }^{104}$ The report supported pilot screening studies through early provision of advice, reviews proportionate to the level of risk presented by a project, the establishment of REC centres within certain geographic areas of England, and a reduction in the number of RECs in England to 120 by 2006, with further rationalization thereafter. The COREC report also recommended removing the nominal distinction between MRECs and LRECs, and that MREC appointing authorities be transferred to be in line with those for LRECs. ${ }^{105}$ Though the COREC report did not take up the Lord Warner Report's recommendation to establish Scientific Officers, it did recommend the creation of a 'new independent group of national research ethics advisers' who would:

ensure that full committees consider only those studies needing intensive scrutiny. They will be able rapidly to review studies with minimal ethical dimensions as an executive research ethics sub-committee. In England, one or more of these sub-committees will specialise in streamlined review. National research ethics advisers will also be able to support the development of the service by providing training, advice and feedback to RECs and applicants. ${ }^{106}$

\footnotetext{
102 ibid para 11.

103 ibid Recommendation, para 1.

104 Central Office for Research Ethics Committees, Building on Improvement: Implementing the Recommendations of the Report of the Ad Hoc Advisory Group on the Operation of NHS Research Ethics Committees (National Patient Safety Agency 2006) [hereinafter COREC Report].

105 In practice, the distinction between MRECs and LRECs ended in 2004, but many RECs still maintained the nominal titles for a number of years thereafter.

106 COREC Report (n 104) 8. Crucially, as discussed later, this recommendation was never implemented.
} 
The COREC report, like the Lord Warner Report, signalled an explicit governmental effort to streamline regulations and make the regulatory approvals and governance process smoother for researchers to promote high-quality research and national economic benefit.

Several substantial operational and procedural developments occurred within and outwith RECs following COREC's 2006 report to improve the research landscape and ethics review service, and respond to concerns outlined above that RECs were under-regulated but, ironically, also burdensome from a regulatory perspective.

In April 2006, the UK government established the National Institute for Health Research (NIHR) to better fund and support clinical and applied health and social care research, as well as research infrastructure in the NHS. While not directly impactful on RECs, the creation of NIHR signalled the government's intention to position health research as a key driver of the UK's economy. This, in turn, necessitated reforming other aspects in health research regulation to facilitate the realization of research findings into innovations. In April 2007, NRES was established, incorporating both COREC and NHS RECs in England as a means of maintaining a UK-wide regulatory framework for ethics review of research within the NHS.

That same year, the Shared Ethical Debate (ShED) ${ }^{107}$ scheme was piloted; it became operational in 2008. The scheme works whereby selected RECs are provided with a real research application (for which consent has been given for its use in the scheme by the investigator) to review as part of their full REC meeting. These RECs review the application as a normal application, recording the discussion and decision in the minutes. The resultant minutes are analysed and the results fed back to the participating RECs, HRA operational teams, the National Research Ethics and Advisors' Panel (NREAP), and the HRA training department in order to develop HRA policies and guidance. ShED has more recently been supplemented with a 'Single Issue Debate', whereby individual RECs are given a short series of questions to respond to concerning a topic (e.g. consent in observational studies), and the responses from the REC are sent back to the HRA for evaluation. ShED's main aim over the years has been to address consistency among RECs and develop standards in ethics review. ${ }^{108}$ Other aims are to identify and

107 Health Research Authority, 'Quality Assurance' <www.hra.nhs.uk/aboutthe-hra/governance/quality-assurance/> accessed 23 October 2019.

108 Hugh Davies, 'Standards for Research Ethics Committees: Purpose, Problems and Possibilities' (2008) 4 Research Ethics Review 152; Peter Heasman and others, 'Helping Research Ethics Committees Share Their Experience, 
build consensus on an ethics issue (and the need for possible guidance to applicants and REC members); identify issues in REC processes (i.e. problems regarding minutes); and identify training needs for REC Chairs and members. ${ }^{109}$

Along the same lines, NRES established in 2007 a three-year rolling accreditation programme to audit RECs against agreed standards as detailed in the SOPs and GAfREC. Still ongoing, as with ShED, RECs are issued with an audit decision (now by the HRA) that is either full accreditation, accreditation with conditions (low risk non-compliance identified requiring an action plan), or provisional accreditation (high and low risk issues requiring an action plan). More recently, this has been coupled with 'quality control' checks by HRA Operational Managers, who undertake six-monthly quality control checks on RECs against agreed standards. This includes an annual observation of a REC meeting.

In 2009, NREAP was established. NRES was originally asked by the four UK Health Departments, through the UKECA, to establish a central advisory panel to help with the strategy, quality assurance, and service development of RECs and improve the research environment in the UK. ${ }^{110}$ NREAP remains an independent body, but is hosted within the HRA (previously NRES). It serves as a resource to provide advice and support to all RECs funded by the UK Health Departments, ${ }^{111}$ as well as appointing authorities in exercising their responsibilities under the GAfREC and SOPs.

In 2010, following the earlier pilot study from 2009 based on the recommendation from the Lord Warner Report, the Proportionate Review Service (PRS) was introduced across the UK. This PRS allows researchers whose studies present "no material ethical issues'112 - previously determined initially by the researcher (who requested to book their application for Proportionate Review), now determined by RES staff, ${ }^{113}$

Learn from Review and Develop Consensus: An Observational Study of the UK Shared Ethical Debate' (2011) 7 Research Ethics 13.

109 Collett (n 56) 6.

110 ibid.

111 Health Research Authority, 'The National Research and Ethics Advisors' Panel (NREAP)' <www.hra.nhs.uk/about-us/committees-and-services/nreap/> accessed 23 October 2019.

112 The HRA defines 'no material ethical issues' as having 'minimal risk, burden or intrusion for research participants'. See Health Research Authority, 'Proportionate Review: Information and Guidance for Applicants' <www.hra.nhs. uk/documents/2017/01/proportionate-review-information-guidance-document.pdf> accessed 17 October 2019.

113 Health Research Authority, 'Proportionate Review' (n 112). 
followed by REC members via a Proportionate Review sub-committee rather than at a full meeting of a REC - to not have to wait as long for a REC opinion as researchers with more 'ethically complex' studies. Indeed, the aim of Proportionate Review is to deliver the final opinion letter to the applicant within 21 calendar days of receipt of a valid application.

Finally, a key infrastructural change in the first decade of the millennium was the move in 2008 of the NRES online form to IRAS, ${ }^{114}$ the online application system used to apply for most permissions and approvals for research in health and social care in the UK. In May 2014, IRAS was further modified to interact with the newly established REC Central Booking System and, for the first time, to allow for electronic submission of applications. IRAS is seen as providing multiple benefits for researchers, not the least of which is streamlining the research application process by enabling researchers to enter information about their project once instead of duplicating information in separate application forms. Other benefits include using filters to ensure that the data collected and collated are appropriate to the type of project, and consequently the permissions and approvals required; and helping researchers meet regulatory and governance requirements. IRAS allows researchers to use a 'Project Filter' to select the type of research and enable other sections and forms relevant to their project (e.g. ionizing radiation, new/existing tissue samples, adults unable to consent) to appear. The IRAS NHS REC application form, and especially the questions it poses to researchers, has become central to the work of RECs, as will be seen later in this book.

\subsection{Ongoing Criticisms and the 2011 Academy of Medical Sciences Report}

At this point in the historical tracing, it would be beneficial to step back and situate the criticisms of and reforms to RECs in a broader context. If many in society support the concept of prospective ethics review of a research project by a committee of qualified people, many others have not supported the past practices of RECs. For as long as they have existed, RECs have been the source of opprobrium by the research community and other commentators, mainly because they are seen as under-, over- or simply mis-regulated bureaucratic bulwarks against otherwise ethical, minimally risky, or non-risky research. Empirical

114 IRAS <www.myresearchproject.org.uk/>. 
research has indicated a high level of variation of decision-making processes in RECs ${ }^{115}$ and dissatisfaction from various stakeholders. ${ }^{116}$

Many of the problems encountered in RECs have been due paradoxically to accusations of both weak regulation and decentralization (leading to duplicative review, procedural inconsistency, and substantive inconsistency of decision-making), and also over-regulation and centralization (leading to cumbersome rules and complex thickets of disproportionate regulation for minimal risk research). Yet, unlike other jurisdictions, RECs in the UK remain governed relatively lightly through statutory regulation. RECs hold a long tradition of independence from central or institutional control. Indeed, that NHS RECs are not formally associated with any specific research institution is what distinguishes them most from US IRBs and Canadian REBs that also evaluate research involving patients in hospitals and healthy volunteers. Though RECs in the NHS system have existed sporadically and informally since the late 1960s, as discussed, they had no formal standing until guidance was put forth by the Department of Health in 1991, and it must be emphasized that this was merely guidance, backed with no legal enforceability. Effectively, these guidelines were the standards governing their practice, though RECs had the discretion to exercise their judgement as to what their primary function should be-and indeed some did not abide by or accept the guidelines. ${ }^{117}$ As a consequence, RECs were permitted to thrive and self-regulate independently. Across the UK, local RECs created separate fiefdoms of customs, standards, and rules that caused, it is said, administrative nightmares for researchers embarking on multi-site and even single-site studies.

The response by the UK government in the last decade to the criticism against RECs and health research regulation more broadly has been to streamline the regulation of health research, and to make the regulation

115 See e.g. Bernard Barber and others, Research on Human Subjects: Problems of Social Control in Medical Experimentation (Russell Sage Foundation 1973); Mary Dixon-Woods and others, 'Written Work: The Social Functions of Research Ethics Committee Letters' (2007) 65 Social Science \& Medicine 792.

116 See e.g. Paul Benson, 'The Social Control of Human Biomedical Research: An Overview and Review of the Literature' (1989) 29 Social Science \& Medicine 1; Konrad Jamrozik, 'The Case for a New System for Oversight of Research on Human Subjects' (2000) 26 Journal of Medical Ethics 334; Charles Warlow, 'Clinical Research Under the Cosh Again' (2004) 329 BMJ 241.

117 Neuberger (n 49). 
more proportionate so as to facilitate (ideally) more research and greater economic prosperity. ${ }^{118}$

The persistent criticism levelled against the clogged regulatory space of 'human subjects research' was evidently (and some would add, eventually) heard by the UK government. In March 2010, the then-ruling Labour government (through the Minister of Health Andy Burnham) asked the AMS, an independent body in the UK founded in 1998 that represents medical science, to undertake a 'rapid independent review' of health research amid concern that strict regulation was driving research abroad. ${ }^{119}$ The Academy convened a work group of senior doctors and scientists; only 3 of the 19 members were drawn from outside the NHS or the biomedical research sector. Its now well-cited report, $A \mathrm{New}$ Pathway for the Regulation and Governance of Health Research, ${ }^{120}$ published only several months later in January 2011, found much to criticize and sounded alarm bells: 'UK health research activities are being seriously undermined by an overly complex regulatory and governance environment', 121 it intoned, and there was no evidence of improved participant or patient safety attributable to the regulatory framework.

The AMS report recommended that the UK's regulation and governance framework around health research be underpinned by four principles, the first two of which were 'to safeguard the well-being of research participants', and 'to facilitate high-quality health research to the public benefit'.122 Crucially, similar to the RCP Guidelines but dissimilar to the GAfREC and first edition of the RGF, when it came to discussing recommendations for RECs, the report pinned them with two equal responsibilities: 'Research proposals are reviewed [by RECs] to consider whether they provide sufficient protection for the interests and safety of research participants and to enable ethical research that is of benefit to society.' ${ }^{123}$

118 Jean McHale, 'Reforming the Regulation of Health Research in England and Wales: New Challenges: New Pitfalls' (2013) 1 Journal of Medical Law and Ethics 23 .

119 Donald Asprey, 'UK Government Asks Academy to Review Regulation of Research' (2010) 340 BMJ c1770.

120 Academy of Medical Sciences, A New Pathway for the Regulation and Governance of Health Research (Academy of Medical Sciences 2011).

121 ibid 5.

122 ibid 6. The other two principles were: '3. To be proportionate, efficient and coordinated. 4. To maintain and build confidence in the conduct and value of health research through independence, transparency, accountability and consistency' (ibid).

123 ibid 73. 
Though RECs came away relatively unscathed in the AMS report, the health research regulatory and governance environment as a whole was seen by the AMS in need of substantial pruning, including the need for 'a proportionate approach to ethics review' in line with US and Canadian approaches. ${ }^{124}$ With respect to ethics review, the AMS report found that:

High ethical standards in research can only be partially achieved through regulation and governance and researchers need support to identify and address the ethical issues arising in their research, outside of applying for an ethics opinion. In addition to the need to embed a proportionate approach within the ethics system, including implementation of 'proportionate review' following the NRES pilot, we recommend that [...] NRES should lead on improving support and advice for researchers by providing centralised, coordinated guidance and training on ethical issues for health researchers. Institutions engaged in health research should also improve the local availability of ethics advice and the training of local support staff. ${ }^{125}$

Significantly, the AMS report recommended the establishment of an independent, central 'Health Research Agency' 'to rationalise the regulation and governance of all health research'. ${ }^{126}$ It also recommended the establishment of a National Research Governance Service within the proposed HRA to perform all project-wide NHS governance (i.e. R\&D) checks and recommend research projects as suitable for undertaking within the NHS. In the AMS's view, the HRA would be capable of providing 'the necessary oversight and impetus' to oversee the regulation and governance of health research, as well as 'removing complexity and streamlining the pathway as a whole'. ${ }^{127}$ It would also provide a 'home for some aspects of regulation and governance that urgently require better coordination and clearer governance'. ${ }^{128}$ Other recommendations included providing greater access to patient data for research while protecting individuals' interests and embedding a culture that would value research within the NHS.

124 ibid 76.
125 ibid 79.
126 ibid 7. The AMS report acknowledged that the proposal for a 'Health Research Agency' was a development of the Department of Health's recommendation in its July 2010 report to create a single regulator of health research. See Department of Health, Liberating the NHS: Report of the Arm's-Length Bodies Review (Department of Health 2010).

127 AMS (n 120) 100.

128 ibid. 


\subsection{Government Response: 2011 - Present}

The coalition Conservative-Liberal Democrat government quickly took up the AMS report's recommendation as announced that same year in its March 2011 budget statement, ${ }^{129}$ agreeing with the report's findings and emphasizing the economic gains to be reaped through streamlining of regulation: 'The complexity of health research regulation and governance has increased over the last twenty years through successive legislative changes. National complexity was then compounded by diverse local approval systems, inconsistent, sometimes risk-averse, local interpretations, and confusion about the standards for compliance that apply to different types of research.' ${ }^{130}$ The government announced that it would:

set up a new health research regulatory agency to streamline regulation and improve the cost-effectiveness of clinical trials. [...] At national level, the Government will create a health research regulatory agency to combine and streamline the approvals for health research which are at present scattered across many organisations. This will reduce the regulatory burden on firms, improve the timeliness of decisions about clinical trials and hence the cost-effectiveness of their delivery in the UK, and has clear support from the Academy of Medical Sciences Review of health research regulation and governance. As a first step, the Government will establish this year a Special Health Authority with the National Research Ethics Service as its core. The new agency will work closely with the Medicines and Healthcare products Regulatory Agency to create a unified approval process and promote proportionate standards for compliance and inspection within a consistent national system of research governance. ${ }^{131}$

Thus, the HRA was established by the UK government as a central health research regulator for the UK and a one-stop-shop for approvals and accompanying guidance. ${ }^{132}$ As recommended by the AMS, and which was presumably already in line with the government's wishes, the HRA was created rapidly-on 1 December that same year-as an interim

129 HM Treasury, Department for Business Innovation \& Skills, Plan for Growth (HM Treasury 2011) 91.

130 ibid.

131 ibid 92.

132 The UK government created the HRA in part, though, because the National Patient Safety Agency had recently been abolished. See HL Deb 15 November 2011, vol 732, col GC219. This said, the HRA was expected to act more boldly than NRES and the NPSA. 
Special Health Authority. ${ }^{133}$ The creating order made clear the HRA's role in promoting research:

\section{Functions of the Authority}

3.-(1) The Authority is to exercise-

(a) such functions in connection with-

(i) the facilitation and promotion of research;

(ii) the establishment of Research Ethics Committees, and the appointment and indemnification of members of Research Ethics Committees; and

(b) such other functions;

as the Secretary of State may direct. ${ }^{134}$

In May that year, the GAfREC was revised. Taking up the AMS report's call for a more proportionate ethics review, the revised second edition of the GAfREC introduced several streamlining moves, including the removal of required REC review for certain types of research (e.g. research involving NHS staff recruited by virtue of their professional role; research limited to use of or access to a care organization's premises or facilities). At the same time, however, it retained the language about primary and secondary responsibilities of RECs. (A new edition of the GAfREC was issued in 2018 but it is primarily a technical update to take account of legal, policy, and operational developments since the previous version was issued.)

Since its formation in December 2011, the HRA's mission has been to promote and protect the interests of patients, streamline regulation, and

133 The Health Research Authority (Establishment and Constitution) Order 2011, 2011 No 2323. See also the Health Research Authority Regulations 2011, 2011 No 2341. The HRA was abolished as a 'Special Health Authority' in the Care Act 2014, s 109(3), when it became a statutory body corporate (i.e. Non-Departmental Public Body) as of 1 January 2015. See the Care Act 2014 (Health Education England and the Health Research Authority) (Consequential Amendments and Revocations) Order 2015, SI 2015/137 and see also SI 2014/3090. It is important to note that the Health Research Authority (Establishment and Constitution) Order 2011 applied in relation to England only. The HRA's legal remit covers England only; however, it works closely with the devolved administrations in Scotland, Wales, and Northern Ireland to support UK-wide compatibility.

134 The Health Research Authority (Establishment and Constitution) Order 2011, s 3(1). 
promote transparency in health and social care research. ${ }^{135}$ Proportionate regulation and streamlined research processes are a driving aim of the HRA. Emphasis on research promotion was reflected explicitly in statutory regulation for the first time in the Health and Social Care Act 2012, which imposed new duties on the Secretary of State for Health and Clinical Commissioning Groups to promote research relevant to the NHS and to use the evidence obtained from such research. ${ }^{136}$ Emphasis on research promotion is further reflected most pronouncedly in the most recent change in the regulatory apparatus of RECs (at least in England) the Care Act 2014, which is a watershed piece of statutory regulation of health research. ${ }^{137}$ It established the HRA as a Non-Departmental Public Body to foster the HRA's UK-wide responsibility for health and social care research governance. ${ }^{138}$ The main objective of the HRA in exercising its functions is stated in the Care Act 2014 as twofold:

(a) to protect participants and potential participants in health or social care research and the general public by encouraging research that is safe and ethical, and

(b) to promote the interests of those participants and potential participants and the general public by facilitating the conduct of research that is safe and ethical (including by promoting transparency in research). ${ }^{139}$

In exercising its functions, the HRA-under the law-'must promote the co-ordination and standardisation of practice in the United Kingdom relating to the regulation of health and social care research; and it must, in doing so, seek to ensure that such regulation is proportionate' ${ }^{140}$ The Care Act 2014 requires the HRA and eight key regulators and government bodies involved in health research to "co-operate with each other in the exercise of their respective functions relating to health or social care research, with a view to co-ordinating and standardising practice relating

135 Health Research Authority, 'About Us' <www.hra.nhs.uk/about-us/whatwe-do/> accessed 17 October 2019 and Health Research Authority, 'Our Vision \& Purpose' <www.hra.nhs.uk/about-us/what-we-do/our-vision-purpose/> accessed 17 October 2019.

136 NHS Act 2006, ss 1E, 14Y.

137 Most of the provisions in the Care Act 2014 extend only to England, save where specified otherwise. But see Care Act 2014, Explanatory Notes, Territorial Extent and Application (paras 34-54).

138 Care Act 2014, s 109. The HRA became a statutory body corporate on 1 January 2015.

139 ibid s 110(2).

140 ibid s 111(3). 
to the regulation of such research'. ${ }^{141}$ Similarly, the Act states that the 'HRA and each devolved authority must co-operate with each other in the exercise of their respective functions relating to the regulation of assessments of the ethics of health and social care research, with a view to co-ordinating and standardising practice in the United Kingdom relating to such regulation'. ${ }^{142}$

The Act also speaks directly to RECs in sections $112-15$. The HRA is authorized by the Act to recognize, establish, and abolish RECs in England ${ }^{143}$ and 'must ensure' that these RECs 'provide an efficient and effective means of assessing the ethics of health and social care research' ${ }^{144}$ In other words, the HRA now has statutory power to directly manage RECs, including, for example, the power 'to require RECs to impose conditions on approvals for clinical trials'. ${ }^{145}$ The HRA must publish a 'REC policy document' (currently the GAfREC) that 'specifies the requirements which it expects research ethics committees it recognises or establishes [...] to comply with' and 'must monitor their compliance with those requirements'. ${ }^{146}$ The HRA is also empowered to 'do such other things in relation to research ethics committees it recognises or establishes [...] as it considers appropriate'. ${ }^{147}$ Explicitly mentioned examples include: 'co-ordinate their work; allocate work to them; develop and maintain training programmes designed to ensure that their members and staff can carry out their work effectively; and 'provide them with advice and help (including help in the form of financial assistance)'. ${ }^{148}$

In sum, the Care Act 2014 has explicitly imported the rhetoric of participant protection and research promotion-language that has evolved from RCP Guidelines, literature from the research and academic community, commissioned reports, and governmental policy-to statutory regulation governing a central regulatory body that has direct managerial oversight of RECs. It is clear that the Care Act 2014 seeks to promote the collective value of health research through streamlining regulation.

\footnotetext{
141 Care Act 2014, s 111(1).

142 ibid s 111(4).

143 ibid s 115.

144 ibid s 112(1). See also s 110(1)(b) ('The main functions of the HRA are [...] functions relating to research ethics committees').

${ }_{145} R$ (on the application of Richmond Pharmacology Ltd) $v$ The Health Research Authority [2015] EWHC 2238 (Admin), para 4.

146 Care Act 2014, s 112(3).

147 ibid s 112(4).

148 ibid.
} 
Certainly, this reflects a broader push by the UK government, which through its statutory and thus binding Regulators' Code, requires regulators to 'avoid imposing unnecessary regulatory burdens through their regulatory activities', to 'choose proportionate approaches to those they regulate', and to consider, among other things, 'how they might support or enable economic growth for compliant businesses and other regulated entities'. ${ }^{149}$

What remains unclear, however, is how the HRA intends to 'streamline' regulation and deliver 'proportionate' regulation through the practical work of those regulators it governs, namely RECs. The AMS's report from 2011 recommended that the HRA 'should lead on the development of proportionate approaches to regulation and governance that take into account the benefits and risks of a research study, rather than applying a "one-size-fits-all" model. This should be embedded through a new edition of the Research Governance Framework.' ${ }^{150}$ As the RGFs from each of the four nations have now been transformed into a harmonized UK Policy Framework for Health and Social Care Research, through what regulatory approach(es) will the HRA manage RECs? In turn, will RECs heed the HRA's steering (i.e. catalysing) or rowing (i.e. controlling) role-and what will be the response for RECs and other regulatory actors outside of England?

Based on white papers and policy papers from the Scottish and English governments over the past few years, there seems to be a strong degree of consistent approach. The Department of Health and Social Care has published several policy papers advocating further system efficiencies, such as a governmental commitment to simplify how research is regulated as part of our plans to increase innovation in medical science'; ${ }^{151}$ and bestowing upon 'the NHS a duty to encourage medical research, so more patients have the chance to take part in clinical studies'. ${ }^{152}$ The most recent NHS Constitution for England now reflects this, stating: 'The NHS aspires to the highest standards of excellence and professionalism [...] through its commitment to innovation and to the promotion, conduct and use of research to improve the current and future

149 Department for Business, Innovation and Skills, Regulators' Code (UK Government 2014). The Regulators' Code came into statutory effect on 6 April 2014 under the Legislative and Regulatory Reform Act 2006.

150 Academy of Medical Sciences (n 120) 89.

151 Department of Health, Policy Paper: 2010 to 2015 Government Policy: NHS Efficiency (UK Government 2010).

152 ibid. 
health and care of the population', and that the NHS 'pledges [...] to inform you of research studies in which you may be eligible to participate'. ${ }^{153}$

Likewise, but even more resoundingly, the Scottish Government released a report in 2015 stating while it was pleased with its nation's ethics review system, further efficiencies could be gained: 'it is imperative that Scotland continues to lead the agenda on streamlining the approvals process and reducing bureaucracy; and there is scope for further improvement'. ${ }^{154}$ To that end, the Scottish Government announced that the CSO would seek to combine the Scottish RES and NHS Research Scotland (NRS) R\&D Offices into a 'single integrated service for researchers while retaining the independence of the REC decision making function'; that the CSO would arrange for 'shared access to study data for ethics and R\&D staff through the HRA's HARP database, streamlining access to electronic documents for R\&D staff throughout Scotland'; that the CSO would 'work with the HRA to revise the Research Governance Framework and implement an efficient ethics and R\&D permission system across the UK that both builds on the efficiencies already delivered through [NRS] and operates seamlessly for sponsors and researchers across the UK'; and that the CSO would 'refocus the early contact of ethics and NHS R\&D staff with researchers on facilitating study approvals, with named R\&D contacts being given to support the researcher in obtaining those approvals'. ${ }^{155}$ As of the time of writing, this merger of the Scottish RES and NRS R\&D Offices has not occurred.

As Hedgecoe writes, even as the REC SOPs have allowed for some regulatory control over REC processes by the state, 'the content of REC decisions remains largely outside Department of Health control' ${ }^{156}$ The HRA and CSO do not have the legitimacy or statutory authority to directly amend statutory regulation, and the independence of NHS RECs is a highly cherished value, as reflected in the Scottish white paper mentioned above. What the HRA and CSO can do, though, is transform the health research process by amending regulatory instruments affecting RECs, and acting itself, or helping RECs and the actors therein act, as a

153 Department of Health, The NHS Constitution for England (UK Government 2015).

154 Scottish Government, Delivering Innovation Through Research: Scottish Government Health and Social Care Research Strategy (Scottish Government 2015) 11.

155 ibid $16-17$.

156 Hedgecoe, 'A Deviation from Standard Design?' (n 45) 74. 
steward for researchers to guide them through the process (i.e. the multiple stages) of embarking upon a health research project.

The HRA is working closely with its equivalent regulatory bodies in the devolved nations to foster education and training for REC members, staff, and the research community. ${ }^{157}$ It is also working to foster harmonization of ethics review processes through its publishing of multiple policies and guidance documents, and through HRA Approval, which is largely an instantiation of the recommendation in the 2011 AMS report to create a National Research Governance Service within the HRA. ${ }^{158}$ Indeed, greater harmonization and simplification of forms is most recently manifest in the HRA's announcement in 2017 that a combined IRAS form that merges the REC and R\&D forms, previously only in place for projects where the lead NHS R\&D office is based in England, would be available for use across the UK, saving time and effort for applicants and sponsors and helping to build UK-wide consistency. ${ }^{159}$ Almost certainly these arrangements will further assuage many of the concerns levelled against RECs over the years. Indeed, as this Chapter 3 has emphasized, fewer criticisms are levelled against ethics review and RECs today.

Consequently, many of the long-standing criticisms of RECs have been quelled, first through influential reports authored by the research community itself in the past decade that were directly taken up by the government, and more recently, through the alignment of the research community, industry (particularly as sponsors or funders of research), and government in designing a regulatory regime that optimizes competition (through efficiency and accelerated review pathways) and economic gain. This does cause one to wonder, though: how, if at all, does this next-generation regulatory reform impact the independence and primary function of RECs, which must, under the stewardship of the HRA and its mandate to streamline regulation, work to "provide an efficient and effective means of assessing the ethics of health and social care research'? ${ }^{160}$ As Kerrison and Pollock remarked a decade ago following the passage of the Clinical Trials Regulations 2004 and the creation of the UKECA, 'by taking control of the ethics review, a

\footnotetext{
157 See e.g. Health Research Authority, 'Learning' <www.hra.nhs.uk/ planning-and-improving-research/learning/> accessed 17 October 2019.

158 Academy of Medical Sciences (n 120) 83.

159 Health Research Authority, 'Four Nations NHS/HSC Compatibility Programme' <www.hra.nhs.uk/about-us/partnerships/four-nations-compatibilityprogramme/> accessed 17 October 2019.

160 Care Act 2014, s 112(1).
} 
government intent on seeing biomedical research as an economic driver will be in a good position to ensure that [ethics] committees do not raise difficult ethical barriers to such research'. ${ }^{161}$ Increased regulatory speed, coded as 'efficiency' and embedded in the regulatory documents governing RECs and in the practices of RECs, certainly begs questions about the role of industry promoting competitive edges and in the wider implications of such a regulatory feature in health research.

\section{CONCLUSION}

In this chapter, I have argued that while the value and REC role (or responsibility) of research promotion has emerged as a recent statutory phenomenon in health research regulation, perhaps as a kind of beacon to encourage a more proportionate or streamlined approach to regulating health research, it has nevertheless existed throughout the history of RECs, appearing in various disguises alongside the role of participant protection. I have also argued that, having become entrenched in the regulation of health research for more than half a century, and through 'steady, incremental institutional change', ${ }^{162}$ RECs are now governed by the government and by central regulatory agencies, administrative staff and offices, standardized forms and communications, lengthy governance arrangements, ${ }^{163}$ and SOPs - the latest version of which stands at a daunting 302 pages. ${ }^{164}$

As advisory but fundamentally research gatekeeping bodies, RECs are a key node situated in the health research regulatory space. The criticisms levied against them have been intense, historically marked by concerns of both under-regulation of RECs and over-regulation by RECs of research projects. As one REC member observed after 20 years of service:

In the 1980s the research ethics world seemed much simpler. The Declaration of Helsinki informed our discussions and decisions, and we supplemented this when the need arose from those few guidelines that existed. We weren't hamstrung by 'Europe,' acts of parliament, regulations, and a clock obsessed set of standard operating procedures; nor were we working in a climate of constant criticism. I feel increasingly caught between a rock and a hard place

\footnotetext{
161 Kerrison and Pollock (n 84) 488.

162 Hedgecoe, 'Scandals' (n 52) 590.

163 See GAfREC (n 2).

164 See Health Research Authority, Standard Operating Procedures for
} Research Ethics Committees (Version 7.4, Health Research Authority 2019). By comparison, version 1.0, released in March 2004, was 182 pages. 
as we try to protect patients from silly research and researchers from silly regulations. ${ }^{165}$

What we have seen in the UK is a march, aided by health research interest groups such as the AMS, towards significant regulatory reform underpinned by a neoliberal discourse stressing market rationality and economic optimization. Hedgecoe suggests that ethics review is a form of 'professional self-regulation without a profession', where 'the overall aim of such review centers on the needs of researchers and research funders, as opposed to the idea that ethics review is driven by the need to increase protection for research subjects'. ${ }^{166}$ Later chapters will test that claim. Undoubtedly, the march towards reform has culminated recently in a turn towards the law for a facilitative remedy - as indeed law is often seen as the ultimate guide for bringing order to rough regulatory terrain. Law, seen in the Care Act 2014, is viewed as a beacon of clarity and power, providing the HRA a firm legal footing and a legal mandate, albeit set within a flexible framework, for streamlining health research regulation and facilitating research.

But law alone cannot provide a complete remedy for the concerns expressed by so many for so many years. Ethical judgements and the workings of these committees of diverse individuals must operate in the regulatory gap that exists between documented law and everyday practice, and in the space between protection and promotion. The Care Act 2014, GAfREC, SOPs, and the UK Policy Framework alone cannot dictate the behaviour and everyday practices of RECs. As we will see, ethical behaviour and regulatory stewardship practised by regulatory actors must be co-produced with regulation, as indeed health research regulation and ethical judgement are co-dependent.

The critical questions that arise from the historically grounded argument laid out in this Chapter 3 are as follows:

(1) What is the nature of the regulation that now governs RECs?

(2) In turn, what is the nature of RECs' approach towards reviewing research projects, and what do these practices and ethical judgements look like against the backdrop of recent regulatory reform at the national and international level that seeks to promote a more proportionate and streamlined regulatory approach?

165 George Masterton, 'Two Decades on an Ethics Committee' (2006) 332 BMJ 615.

166 Hedgecoe, 'Scandals' (n 52) 591-2. 
(3) More broadly, what ought a regulatory framework for realizing the objective - or reconciliation — of participant protection and research promotion look like?

In the next chapter, I explain how these questions were addressed in my empirical research, guided by qualitative research methods and a methodology informed by regulatory theory and anthropology-what I term an anthropology of regulation. 